\title{
Brittle words: the impact of health information on patients' compliance with treatment
}

\author{
ANDREW HAMPSON \\ Library, University of Reading
}

\section{Introduction}

There are numerous benefits associated with the provision of consumer health information. Ley ${ }^{(1)}$ suggests that it increases satisfaction with, and participation in, the health care process, thus positively impacting on compliance with treatment. However, Maslow maintains that health information can prompt non-compliance with treatment as patients access information sources beyond the general practitioner's surgery:

Some women trust their physicians and other health care professionals to provide good advice about treatments, but others are suspicious and trust the media reports instead. ${ }^{(2)}$

Previous research into the impact of health information has focused on how it influenced the clinical decision-making of hospital doctors ${ }^{(3)}$. The same questions need to be answered about the impact of consumer health information on patient behaviour, as it has been estimated that $40 \%$ of patients do not comply with doctor's advice on treatment ${ }^{(4)}$.

\section{Aim}

A study was undertaken to investigate the impact of health information on patients' compliance with treatment for postmenopausal osteoporosis.

\section{Objectives}

- To establish what sources of health information, related to osteoporosis, have been accessed by women in the sample population.

- To determine whether health information influences patients' compliance with recommended lifestyle changes and prescribed treatment related to osteoporosis.

\section{Methodology}

A three month study was undertaken as a joint venture with Dr Michael Kirby from April - June 1995. Seventy women attending a menopause clinic based in a Letchworth general practice were surveyed, using a postal questionnaire and open-ended standardised interviews. The sample population was divided into two categories:

- 35 women with normal bone mineral density(Normal BMD), who had been issued with information by the general practitioner and menopause clinic nurse on preventive measures relating to changes in diet and lifestyle. 
- 35 women with low bone mineral density(Low BMD) who were issued with information relating to changes in diet and lifestyle. They had also been prescribed hormone replacement therapy(HRT) and received information from the general practitioner and menopause clinic nurse about the treatment they were undertaking.

\section{Results}

Questionnaires were sent to 70 women of whom $53(76 \%)$ returned completed questionnaires. There was a significant difference in questionnaire response rate between the two patient groups with the Normal BMD patient group recording $60 \%$ response rate, compared to $91 \%$ response rate for the Low BMD patient group. A total of 19 patients were interviewed.

\section{Sources of health information}

\section{The general practice setting}

There was a high level of satisfaction with the health information provided within the general practice setting in terms of the amount received and relevance to individual situations.

Half of the sample population indicated that the amount of health information provided in the general practice setting was exactly right. Although over $60 \%$ of patients perceived such information to be entirely relevant to their individual situation, there was a marked disparity in patient groups, with over half of the Normal BMD patients indicating that it was partly relevant. This rating could be influenced by health beliefs and the low vulnerability to osteoporosis the Normal BMD group associates with its health situation.

\section{Other sources}

A wide range of information sources were accessed beyond the general practice setting. As can be seen in Table 1, information from magazines and newspapers were accessed by over half of the sample population. The informal interpersonal networks of family and friends were heavily used as sources of health information, but with a significant difference in patient groups. Over $40 \%$ of Low BMD patients used the hospital aș an information source. Normal BMD patients relied on informal networks as they did not have as much contact with health professionals.

\section{Impact on patient compliance}

Almost three quarters of the sample population had changed their behaviour as a result of the health information provided in the general practice setting, as shown in Table 2 . However, there is a significant difference between the two patient groups, with only 57\% of Normal BMD patients changing their behaviour as opposed to $75 \%$ of Low BMD patients. This could be attributed to low vulnerablity to osteoporosis perceived by the Normal BMD patient group.

Table 3 shows that health information enabled patients to improve their understanding of their condition and to follow instructions for prescribed drugs. However, almost half of the Low BMD patients, who had been prescribed HRT, used the health information to assess risk factors. Health information stimulated $47 \%$ of Low BMD patients to ask questions of health professionals, but only $24 \%$ of Normal BMD patients were inclined to do this. 


\section{Conclusion}

Health information has a postive effect on patients' compliance with treatment. It enabled patients to improve their understanding of their condition and to follow instructions for prescribed drugs. Patients understanding of osteoporosis and associated treatments was generally good, except there was some confusion surrounding the risk factors and benefits associated with HRT. Only one quarter of those prescribed HRT perceived that they had received information about risk factors within the general practice setting.

A wide range of information sources were accessed beyond the general practice setting. However, the knowledge patients acquired from such external sources would always be discussed with health professionals in the general practice setting before a change in behaviour was implemented. Health information from sources beyond the general practice setting did not prompt non-compliance, even when it contradicted information disseminated in the general practice. As patients became more informed, particularly of risk factors associated with treatment, they turned to health professionals for advice.

The general practitioner and menopause clinic nurse were identified as the most influential sources of health information affecting patients' compliance with treatment. Patients considered that written health information aided compliance with treatment, as they could refer to it in their own time without restrictions. It supplemented and reinforced the knowledge conveyed by health professionals.

\section{Acknowledgements}

I would like to thank Janet Rolinson and Dr Michael Kirby for their guidance and support throughout this study.

\section{References}

1. Ley, P. Communicating with patients: improving communication, satisfaction and compliance. London : Croom Helm, 1988, p. 110.

2. Maslow, K. Problems in women's knowledge about menopause. Experimental Gerontology, 1994, 29(314), 353.

3. Marshall, J. The impact of information services on decision making: some lessons from the financial and health care sectors. Information Policy Briefings No. 1. London : British Library, 1993.

4. Haynes, R. et al. Compliance in health care. Baltimore : John Hopkins University Press, 1979. 
Table 1: Other Sources of health information accessed by patient group

\begin{tabular}{|l|c|c|}
\hline $\begin{array}{l}\text { Sources of health } \\
\text { information }\end{array}$ & $\begin{array}{c}\text { Normal BMD } \\
(\mathbf{n = 2 1})\end{array}$ & $\begin{array}{c}\text { Low BMD } \\
(\mathbf{n = 3 2})\end{array}$ \\
\hline Magazines & $48 \%(10)$ & $50 \%(16)$ \\
\hline Newspapers & $43 \%(9)$ & $50 \%(16)$ \\
\hline Friends & $48 \%(10)$ & $28 \%(9)$ \\
\hline Hospital & $19 \%(4)$ & $44 \%(14)$ \\
\hline Chemist & $29 \%(6)$ & $34 \%(11)$ \\
\hline TV & $19 \%(4)$ & $34 \%(11)$ \\
\hline Family & $19 \%(4)$ & $31 \%(10)$ \\
\hline Public library & $19 \%(4)$ & $25 \%(8)$ \\
\hline Radio & $14 \%(3)$ & $22 \%(7)$ \\
\hline None & $19 \%(4)$ & $9 \%(3)$ \\
\hline Unclassified & $5 \%(1)$ & $6 \%(2)$ \\
\hline $\begin{array}{l}\text { Consumer health } \\
\text { information centre }\end{array}$ & $5 \%(1)$ & $3 \%(1)$ \\
\hline Other & $10 \%(2)$ & - \\
\hline Self-help group & $5 \%(1)$ & $-11)$ \\
\hline line & & \\
\hline
\end{tabular}

Table 2: Impact of health information provided at the surgery by patient group

\begin{tabular}{||l|c|c|c|}
\hline $\begin{array}{l}\text { Impact of health } \\
\text { information }\end{array}$ & $\begin{array}{c}\text { Normal BMD } \\
(\mathbf{n = 2 1})\end{array}$ & $\begin{array}{c}\text { Low BMD } \\
(\mathbf{n = 3 2})\end{array}$ & $\begin{array}{c}\text { Total } \\
(\mathbf{n}=\mathbf{5 3})\end{array}$ \\
\hline $\begin{array}{l}\text { Changed behaviour } \\
57 \%(12)\end{array}$ & $75 \%(24)$ & $68 \%(36)$ \\
\hline $\begin{array}{l}\text { No change in } \\
\text { behaviour }\end{array}$ & $24 \%(5)$ & $19 \%(6)$ & $21 \%(11)$ \\
\hline Unclassified & $19 \%(4)$ & $6 \%(2)$ & $11 \%(6)$ \\
\hline
\end{tabular}


Table 3: Effect of health information accessed by patient group

\begin{tabular}{|c|c|c|}
\hline \begin{tabular}{|c|c|}
$\begin{array}{c}\text { Effect of health } \\
\text { information }\end{array}$ \\
\end{tabular} & $\begin{array}{c}\text { Normal BMD } \\
(n=21)\end{array}$ & $\begin{array}{c}\text { Low BMD } \\
(\mathrm{n}=\mathbf{3 2})\end{array}$ \\
\hline $\begin{array}{l}\text { Improve } \\
\text { understanding of } \\
\text { condition }\end{array}$ & $38 \%(8)$ & $53 \%(17)$ \\
\hline $\begin{array}{l}\text { Follow instructions } \\
\text { for prescribed } \\
\text { drugs }\end{array}$ & $29 \%(6)$ & $47 \%(15)$ \\
\hline $\begin{array}{l}\text { Stimulate more } \\
\text { questions to ask } \\
\text { GP/nurse }\end{array}$ & $24 \%(5)$ & $47 \%(15)$ \\
\hline Assess risk factors & $24 \%(5)$ & $47 \%(15)$ \\
\hline $\begin{array}{l}\text { Make choices } \\
\text { about treatment }\end{array}$ & $29 \%(6)$ & $38 \%(12)$ \\
\hline Gain reassurance & $24 \%(5)$ & $34 \%(11)$ \\
\hline Assess side effects & $19 \%(4)$ & $31 \%(10)$ \\
\hline $\begin{array}{l}\text { Confirm prior } \\
\text { knowledge }\end{array}$ & $24 \%(5)$ & $28 \%(9)$ \\
\hline Improve life-style & $24 \%(5)$ & $16 \%(5)$ \\
\hline $\begin{array}{l}\begin{array}{l}\text { Refresh memory of } \\
\text { details/facts }\end{array} \\
\end{array}$ & $19 \%(4)$ & $19 \%(6)$ \\
\hline Substantiate what & $5 \%(1)$ & $19 \%(6)$ \\
\hline Nothing & $10 \%(2)$ & $3 \%(1)$ \\
\hline Unclassified & $10 \%(2)$ & $3 \%(1)$ \\
\hline Other & $5 \%(1)$ & - \\
\hline
\end{tabular}

